\title{
Get Wheelin' in Westlawn: Mounting a Bicycling Program in a Low-Income Minority Urban Community
}

\section{Anne Dressel ${ }^{1, *}$, Michael Steinborn ${ }^{2}$ and Keith Holt ${ }^{3}$}

1 College of Nursing, University of Wisconsin-Milwaukee, P.O. Box 413, Milwaukee, WI 53201, USA

2 Silver Spring Neighborhood Center, 5560 N. 64 ${ }^{\text {th }}$ Street, Milwaukee, WI 53218, USA; E-Mail: MichaelSteinborn@maximus.com

3 Milwaukee Bicycle Works, 2015 N. 51 $1^{\text {st }}$ Street, Milwaukee, WI 53208, USA; E-Mail: holt.keith.a@gmail.com

* Author to whom correspondence should be addressed; E-Mail: banda@uwm.edu; Tel.: +1-414-229-3995; Fax: +1-414-229-5541.

External Editor: Eling Douwe de Bruin

Received: 3 October 2014; in revised form: 18 November 2014 / Accepted: 26 November 2014 / Published: 5 December 2014

\begin{abstract}
Located in Milwaukee, Wisconsin, USA, the Westlawn neighborhood is home to the State of Wisconsin's largest public housing development. Westlawn is a low-income, African-American urban community that suffers from a wide range of health and environmental disparities. A community-based participatory action (CBPA) team was formed to address environmental health issues in Westlawn, and found asthma rates there are among the highest in the State. Decreasing air pollution, and corresponding asthma triggers, became a priority for the community. The CBPA team developed a bicycling program to reduce trips made by car and improve air quality in the Westlawn neighborhood. Input from focus group meetings shaped the development, implementation and expansion of the bicycling program. While the program was originally conceived to address environmental health issues, it provided key findings about how to encourage bicycling in low-income minority urban communities.
\end{abstract}

Keywords: bicycling; African-American; community-based participatory action; health disparities 


\section{Introduction}

The Westlawn Partnership for a Healthier Environment is a Level II CARE (Community Action for a Renewed Environment) cooperative agreement with the U.S. Environmental Protection Agency. Founded in 2008, the purpose of the Westlawn Partnership is to bring together community stakeholders to identify and prioritize environmental health risks in Westlawn, and to develop solutions to address those risks. In practice, the Westlawn Partnership for a Healthier Environment is a community-based participatory action (CBPA) team which has grown to include 35 community organizations, including Westlawn residents, private businesses, not-for-profit organizations, schools, universities, elected officials, local media, health centers, religious organizations, and more. Today, the Westlawn Partnership is a thriving CBPA team, dedicated to improving the health and environment of Westlawn and the surrounding community. This paper will discuss the process used to develop a bicycling program in the community, and the lessons learned from that initiative.

\section{Context}

The City of Milwaukee is the commercial and industrial center of, and the most populous city in, the State of Wisconsin, which is in the north-central part of the United States. Located in Milwaukee, the Westlawn neighborhood is the largest, low-income, public housing development in the State. The community includes the Westlawn public housing project, and the surrounding neighborhood within the 53218 postal code, which has 43,494 residents [1]. Ninety-seven per cent of Westlawn's residents are persons of color, of whom 92\% are African-American [1]. Fifty-one percent of Westlawn's residents are children, ages 17 and under. Ninety-three percent of heads of households in Westlawn are female. The current average household income in the development is just $\$ 15,142$ per year compared to $\$ 40,875$ for the City of Milwaukee [2].

The Westlawn neighborhood is an economically-disadvantaged community, with a wide range of environmental risks including: poor air quality resulting from power plant emissions, diesel emissions, and particulate matter from buses and trucks; above national average for chemical releases, number of superfund sites, and lead exposure hazards; and poor water quality affecting the watershed, drinking water, and the beaches surrounding Lake Michigan [3].

Westlawn has a high prevalence of asthma, especially among children. Estimated and self-reported asthma prevalence, annual pollen score, and poverty rates are higher than the national average. Specific to the 53218 postal code, the Wisconsin Department of Health Services reported a rate of 151.31 (per 10,000) hospitalizations for asthma in 2008, compared to a crude rate of 17.58 for Milwaukee County and 9.42 for the State of Wisconsin. Children living in the Westlawn neighborhood are four times more likely to visit an emergency room for asthma attacks compared to the rest of the State; and more than three times more likely to be hospitalized for asthma compared to the rest of the State. Thus, environmental health concerns, especially related to asthma triggers, disproportionately affect the Westlawn community.

Concerns surrounding asthma triggers and air quality led to an interest in developing a bicycling program in the Westlawn community, which was conceived and launched by a group of community 
stakeholders: the Westlawn Partnership for a Healthier Environment Community-Based Participatory Action (CPBA) team.

\subsection{Community-Based Participatory Action (CBPA) Team}

The Westlawn CBPA team was formed in 2008 to identify and address environmental health risks, and has met on a monthly basis since then [3]. Over 60 environmental health concerns were initially identified by the Westlawn CBPA team. After a vetting process [3], the list was narrowed to the top nine environmental health concerns. Four out of the top five concerns were related to asthma triggers, including indoor and outdoor air pollution [3]. This was not surprising, given the high rates of asthma in the community.

The Westlawn CBPA team developed solutions to address the top environmental health risks. One of the proposed interventions was the development of a bicycling program in the Westlawn community. The bicycling program was proposed for several reasons: (a) to encourage community members to make more trips by bike rather than by car, in order to improve air quality; (b) to encourage exercise; and (c) to build strong families by promoting a family-friendly activity for all ages.

\subsection{African-Americans and Cycling}

As previously noted, the Westlawn neighborhood is predominantly African-American, a group which has the lowest rates of cycling in the United States [4]. In addition, the cycling infrastructure in Westlawn in sorely lacking. An arterial road, which borders Westlawn to the north, is a busy four-lane thoroughfare. While bike lanes are painted on that particular road, the traffic is too fast for safe riding. Furthermore, the bike lanes are often covered in broken glass, pot holes, and other hazards.

Safety is also a concern for Westlawn residents, which corresponds to national findings by the League of American Bicyclists. The fatality rate for African-American cyclists, in general, is $30 \%$ higher than for white cyclists [4]. According to the League of American Bicyclists, "Only 9\% of Americans say they will ride on all roads and feel confident riding in traffic. Only $6 \%$ of women and $5 \%$ of African-Americans feel confident riding on all streets with traffic. However, 26\% of people of color said they'd like to ride more but worry about safety in traffic" [4].

Mirroring national trends, disparities exist in access to safe bicycling infrastructure in low-income minority urban communities, such as Westlawn.

\section{Method, Results, Discussion}

\subsection{Method}

The Westlawn CBPA team served as a de facto focus group which provided ongoing input into the development, implementation, and expansion of the bicycling program. The CBPA team sought to increase the perceived benefits of bicycling and decrease the perceived barriers through implementation of a bicycling program: “Get Wheelin' in Westlawn.” Preliminary quantitative and qualitative data were collected at the regular monthly Westlawn CBPA team meetings, and ongoing feedback was incorporated to improve the program. 


\subsubsection{Phase One-Summer 2012}

A lack of bike shops in or near Westlawn was the first barrier to cycling that was identified. The east side of Milwaukee and its affluent suburbs have a variety of bike shops that sell all levels and types of bicycles, have fully-staffed bike repair services, and are open in the evenings and on weekends. Westlawn, however, is located in northwest Milwaukee, and residents do not have easy access to bike shops.

To address this initial barrier, the Westlawn CBPA team launched “Get Wheelin' in Westlawn” in summer 2012, and offered free basic bicycle maintenance and repairs, on a monthly basis, to Westlawn-area residents. The Silver Spring Neighborhood Center (SSNC), a non-profit social service agency located in the heart of Westlawn and founding member of the Westlawn CBPA team, advertised the tune-ups to local residents. The tune-ups took place on public school grounds, which were adjacent to the SSNC. The University of Wisconsin-Milwaukee (UWM) College of Nursing, a founding member of the Westlawn CBPA team, provided a staff member to facilitate the tune-ups, and who secured the services of two experienced bicycle mechanics who volunteered their time, and donated bicycle repair supplies. One of the volunteer mechanics had experience working at a large bike shop and was able to purchase bike repair supplies at reduced cost for the Westlawn tune-ups. In summer 2012, 120 bicycles were repaired free of charge. The results were immediately apparent, with children, especially, becoming a regular sight on their bicycles in the neighborhood. To show their support for the "Get Wheelin' in Westlawn" initiative, the Westlawn Resident Council donated funds for additional bicycle repair supplies.

In summer 2012, the Westlawn CBPA team partnered with Milwaukee Bicycle Works and sponsored "Women Riding in Living Color" monthly bike rides. These rides targeted African-American and Latina women with the goal of getting this demographic comfortable riding their bikes in the city. These women were targeted for two reasons: (a) African-American and Latina women are least likely to ride bicycles [4], and (b) if these women, who are often the key decision-makers of the household, would ride bikes they would in turn, be more open to allowing their children to ride. Rides were held on a monthly basis and alternated between Milwaukee's northwest side (near Westlawn), with a large African-American population, and Milwaukee's south side, with a large Latino population. Eighteen riders participated, and the women were so enthusiastic about the rides that they would drive from the north side to the south side, and vice versa, to participate in the monthly rides.

The rides were also a learning tool for the ride leaders from Milwaukee Bicycle Works, the UWM College of Nursing, and the Bike Federation of Wisconsin (BFW), who had initially planned routes of 15-20 kilometers. After the first ride, however, it was obvious that most of the women were not comfortable at all riding on city streets, changing gears, or using hand brakes. Based on observation and feedback the emphasis instead was placed on teaching women how to shift gears, ride in traffic, and feel comfortable on a bike.

Also in summer 2012, the BFW hosted a two-week Bike Camp in Westlawn free of charge. The Silver Spring Neighborhood Center advertised the bike camp to local children while the BFW provided two trainers to run the camp. The trainers provided the summer Bike Camp participants with both classroom and on-the-road instructions that included helmet safety, introduction to biking, riding in traffic, riding in the road, traffic laws and right of way, intersection management, in-class reviews of all topics covered 
with post-tests, and lastly, post-test review and mapping. Fifteen Westlawn children participated in the 2012 Bike Camp.

During the winter of 2012-2013, the Westlawn CBPA team analyzed qualitative and quantitative results from the summer cycling initiatives. Based on those results, the CBPA team made plans for summer 2013. The Westlawn CBPA team applied for a small grant from the United Neighborhood Centers of Milwaukee Childhood Obesity Prevention Program, and successfully obtained funds to support expansion of the Westlawn cycling program in 2013. The proposal for these funds was written by Westlawn CBPA team members from the UWM College of Nursing and from the Silver Spring Neighborhood Center (SSNC), and the funds were administered by SSNC.

\subsubsection{Phase Two-Summer 2013}

Free bicycle tune-ups were offered again on a monthly basis in summer 2013. As in 2012, the tune-ups were advertised to area residents by SSNC, and staffed by the UWM College of Nursing and volunteer bike mechanics, who were secured by the UWM College of Nursing. UWM College of Nursing staff also contacted one of Milwaukee's newer bike shops, DreamBikes, which provided additional staff and supplies to assist with the tune-ups. With the added support, a total of 172 bicycles were repaired in Westlawn that summer. More encouraging, Westlawn-area residents knew about the program, and there was often a line of children, adults, and their bikes waiting for the tune-ups to start every month. The response from the community was enthusiastic: “Thank you!" was the most often-heard comment. "That's so great that you are doing this!" said a local mother. Seeing the smiles on the children's faces as they rode through the local school's black-topped playground, now that they had a working bike, was the surest sign of the project's success.

Funding from the Childhood Obesity Prevention Program grant also supported the purchase of bike racks for SSNC. The racks were installed in the local elementary school playground, which is adjacent to SSNC. These were the first bike racks to be installed at the local Neighborhood Center or school, and provided additional cycling infrastructure for local residents.

In summer 2013, the BFW once again hosted a summer Bike Camp at SSNC. As in 2012, the primary goal of the bike camp was to promote active living, bicycle safety, to encourage exercise and improve the environment by replacing trips made by car. SSNC advertised the Bike Camp to local children. Thirty children expressed interest, and 17 actually enrolled. SSNC also provided a staff member to ride with the Bike Camp participants, in addition to the BFW staff. All of the riders who completed the program received bike helmets, and eight of the Westlawn children were given bikes to keep by the BFW. One Bike Camp student learned how to ride for the first time. Overall, the Bike Camp was deemed very successful by the BFW and the Westlawn CBPA team. The riders were instructed on and implemented bicycle safety; consistently demonstrated proper bicycle maneuvers and practices; and healthy living and exercise was an obvious outcome of the bike camp, as riders were challenged by rides as long as 25 kilometers.

The Westlawn CBPA team also launched the SSNC Bike Club in Fall 2013, which held weekly group rides. SSNC advertised the rides to the community, the UWM College of Nursing provided the route and ride leader, and two CBPA-team Community Health Workers, who are Westlawn residents, encouraged their neighbors to join the rides, and participated themselves. The SSNC Bike Club grew 
from eight riders the first week, to 17 riders by the last ride of the season. Participants included Westlawn families, the local alderman, Westlawn CBPA team members, and more. For the last ride of the season, two City of Milwaukee bicycle police officers joined the group, and PNC Bank (a Westlawn CBPA team member) provided refreshments after the ride. The UWM College of Nursing provided a senior nursing student who was on-hand to provide first-aid to riders, if needed.

All rides followed the same 6-kilometer route around the Westlawn neighborhood. The rides were family-friendly, so that children could ride the whole distance; although we found that the adults on the rides often struggled more with the distance than any of the children. Riders were enthusiastic about the new Bike Club rides, stating, “That was fun!” and "It was easier this week than last week. I think I might ride every week!”

"Get Wheelin' in Westlawn" also provided free bicycle helmets to whoever needed them at the free bicycle tune-up sessions, at the SSNC Bike Club rides, and as the need arose. Bike helmets were donated by the BFW and stored and distributed by SSNC. A total of 27 helmets were distributed to Westlawn-area children and adults.

\subsubsection{Phase Three-Summer 2014}

"Get Wheelin' in Westlawn” continued in Summer 2014, and free monthly bicycle tune-ups were offered. Due to poor weather on tune-up dates in 2014, however, fewer bicycles were repaired than in the previous summer, with 120 bicycles repaired in 2014. The SSNC Bike Club hosted regular group rides again in summer 2014. Rides were held on a monthly basis in summer 2014, a schedule that was found to be less effective and attracted fewer riders than the weekly Fall rides held in 2013.

Based on feedback from participants and community residents, future plans for the 'Get Wheelin' in Westlawn” program include: (a) continuation of the free, monthly bicycle tune-ups in Westlawn for upcoming summers; (b) training Westlawn youth to do minor bicycle repairs and equip them with a tire pump and tire patch kit so they can provide repairs to community residents for a small fee; (c) grow the SSNC Bike Club and return to the weekly ride schedule; (d) conduct a systematic evaluation of how the "Get Wheelin' in Westlawn” initiative has increased exercise among Westlawn residents, and contributed to fewer trips made by car, thereby improving air quality in the neighborhood. In fact, a group of researchers, which included Westlawn residents, came together in summer 2014 to plan a study to evaluate the impact of bicycling interventions on obesity rates in Westlawn adults. If funded, this study will be conducted in summer 2015.

\subsection{Results}

The biggest success of the "Get Wheelin' in Westlawn” program has been the free monthly bicycle tune-ups, which have allowed Westlawn children and families to have working bicycles to ride. Since the program was launched, 412 bicycles have been repaired, free of charge, for Westlawn community members.

The Summer Bike Camps have provided training to 32 children in Westlawn. Free bike helmets, and in some cases, free bicycles have also been provided to Westlawn community members. "Get Wheelin' in Westlawn” also donated two children's bicycles to a local elementary school each Spring, which were 
given to children through a random drawing at the school carnival each June. Finally, the SSNC Bike Club rides and Women Riding in Living Color group rides attracted a total of 76 riders.

\subsection{Discussion}

\subsubsection{Lessons Learned-Successes}

“Get Wheelin' in Westlawn” was a community-driven initiative. The history and trust among Westlawn CBPA team members, which included Westlawn residents themselves, led to a successful and ongoing program. Based on community feedback voiced at the various activities and during Westlawn CBPA team meetings, the Westlawn CBPA team learned that there is a high level of enthusiasm and support in the community for bicycling initiatives. Community members are looking for ways to get active and healthy, and having planned rides with the SSNC Bike Club and the Women Riding in Living Color groups helped riders feel safe and motivated them to ride.

In response to community requests, the SSNC Bike Club was designated a "family activity" so that parents and children were both involved and rode together with the group. It was important to have activities that the whole family could be involved in, in order to build a stronger and safer community. In addition, the more that parents role-modeled healthy behavior for their children, the more likely children were to engage in healthy behavior themselves. The group bike rides also helped to build a sense of community. Riding on neighborhood streets and saying "hello" to neighbors as we passed forced pleasant interactions that are all too frequently absent in inner-cities in the U.S. In addition, the group rides served as a traffic calming measure. Cars would often slow down, drivers would smile, and wait for the group to ride through an intersection.

As previously noted, the biggest success of "Get Wheelin' in Westlawn” has been the free monthly bicycle tune-ups. These were so successful, that there was often a line of children with their bicycles waiting for the bike mechanics to arrive in Westlawn every month. Without a working bicycle, there is no bicycling program.

Finally, while the program was initially launched as a way to reduce trips made by car and improve air quality in the community, the simple act of pedaling a bicycle made the program successful. Children and adults enjoyed riding their bikes. Working bicycles, bicycle training, and planned group rides helped to facilitate a successful bicycling program.

\subsubsection{Lessons Learned—Challenges and Concerns}

Fast traffic in the community was a concern for the group bike rides. Several Westlawn residents are now working with the local alderman to address issues of speeding in the Westlawn neighborhood. Thus, the bicycling program has become an opportunity to build community capacity and enact change, with Westlawn residents learning the process of how to work with the City of Milwaukee and local politicians to develop traffic-calming policies and improve walking and cycling infrastructure in the neighborhood.

Road conditions in the Westlawn community were less than ideal, with potholes and broken glass. Having the local alderman involved in the group bike rides helped to make him aware of the challenges that cyclists face, which he can address with the local Department of Public Works. It is worth noting 
that after the alderman's rides with the SSNC Bike Club in 2013, some repairs were made to the neighborhood streets in 2014, which helped to improve the roads for cycling.

Lastly, because the bicycle mechanics were so busy during the free bicycle repair sessions, there was no time to train community youth on how to fix the bicycles themselves. One idea was to offer a free clinic over the winter to train local youth, so that they will be able to repair flat tires, which is the biggest problem, for community members in the future.

\section{Conclusion}

The "Get Wheelin' in Westlawn” program provides insights into what makes a bicycling program successful in a low-income African-American urban community. Including community members as part of the planning team, incorporating ongoing community feedback to improve the program, and enlisting the support and expertise of relevant stakeholders are key. The CBPA team approach provided an effective process to develop, implement, and fine-tune the program. CBPA team members relied on each other and contributed different skills and strengths to make the bicycling program successful.

\section{Acknowledgments}

The UWM College of Nursing received \$297,500 from the U.S. Environmental Protection Agency to support the Westlawn Partnership for a Healthier Environment: A Level II CARE Cooperative Agreement with the U.S. EPA. In addition, the Silver Spring Neighborhood Center received an \$800 small grant from the United Neighborhood Centers of Milwaukee Childhood Obesity Prevention Program to support the "Get Wheelin' in Westlawn” program. No funds were received to publish in open access journals.

\section{Author Contributions}

Anne Dressel was the Project Director of the Westlawn Partnership for a Healthier Environment CBPA team. Anne Dressel prepared and wrote the final manuscript. Michael Steinborn was the liaison at the Silver Spring Neighborhood Center for “Get Wheelin' in Westlawn” activities. Michael Steinborn drafted content for the manuscript about the Summer Bike Camps, SSNC Bike Club, and offered editorial suggestions. Keith Holt was the liaison at Milwaukee Bicycle Works for 'Get Wheelin' in Westlawn” activities. Keith Holt drafted content for the manuscript about the Women Riding in Living Color rides, provided input for the Free Bicycle Tune-ups section, and offered editorial suggestions.

\section{Conflicts of Interest}

The authors declare no conflict of interest.

\section{References}

1. U.S. Census Bureau 2009 Statistical Abstract. Available online: https://www.census.gov/ compendia/statab/2009/ (accessed on 4 April 2013).

2. U.S. Census Bureau 2000. Available online: http://www.census.gov/main/www/cen2000.html (accessed on 9 September 2007). 
3. Dressel, A.; Anderko, L.; Koepsel, B. The Westlawn Partnership for a Healthier Environment: Promoting Environmental Justice and Building Community Capacity. Environ Justice. 2013, 4, 127-132.

4. The League of American Bicyclists. Available online: www.bikeleague.org/sites/ lab.huang.radicaldesigns.org/files/equity_report.pdf (accessed on 4 December 2013).

(C) 2014 by the authors; licensee MDPI, Basel, Switzerland. This article is an open access article distributed under the terms and conditions of the Creative Commons Attribution license (http://creativecommons.org/licenses/by/4.0/). 